\title{
L-histidine reduces inhibitory avoidance in Carassius auratus submitted to cerebellar ablation
}

\author{
D.C. Garção and R. Mattioli \\ Laboratório de Neurociências, Universidade Federal de São Carlos, São Carlos, SP, Brasil \\ Correspondence to: R. Mattioli, Departamento de Fisioterapia, Universidade Federal de São Carlos, \\ Rodovia Washington Luiz, km 235, 13565-905 São Carlos, SP, Brasil \\ Fax: +55-16-3361-2081. E-mail: mattioli@ufscar.br
}

\begin{abstract}
The effect of post-training treatment with L-histidine (LH) on the memory consolidation of inhibitory avoidance was investigated in Carassius auratus submitted to cerebellar ablation. The inhibitory avoidance procedure included 3 days: one habituation day, one training day (5 trials, T1-T5) and one test day. On the training day, each fish was placed individually in a white compartment separated from a black compartment by a sliding door. When the fish crossed into the black compartment, a weight was dropped in front of it (aversive stimulus) and the time to cross was recorded. Saline or LH $(100 \mathrm{mg} / \mathrm{kg})$ was injected intraperitoneally 10 min after the trials. Data were $\log _{10}$ transformed and analyzed by ANOVA and the Student-Newman-Keuls test $(P<0.05)$. In T5, all groups [ablation/LH $(\mathrm{N}=15 ; 189.60 \pm 32.52)$, ablation/saline $(\mathrm{N}=14 ; 204.29 \pm 28.95)$, sham/LH $(\mathrm{N}=14 ; 232.36 \pm 28.15)$, and sham/saline $(\mathrm{N}=15 ; 249.07 \pm 25.82)$ ] had similar latencies that were significantly higher than $\mathrm{T} 1$ latencies [ablation/LH (89.33 $\pm 20.41)$, ablation/saline (97.00 \pm 25.16$)$, sham/LH (73.86 \pm 18.42$)$, and sham/saline $(56.71 \pm 17.59)$ ], suggesting acquisition of inhibitory avoidance. For the test, there was a significant reduction in latencies of ablation/LH $(61.53 \pm 17.70)$ and sham/saline $(52.79 \pm 25.37)$ groups compared to the ablation/saline $(213.64 \pm 29.57)$ and sham/LH $(199.43 \pm 24.48)$ groups, showing that cerebellum ablation facilitated retention of inhibitory avoidance and $\mathrm{LH}$ reversed the effect of ablation. The results support other evidence that LH impairs memory consolidation and/or reduces the interpretation of aversion value.
\end{abstract}

Key words: Inhibitory avoidance; L-histidine; Cerebellar ablation; Medial telencephalic pallium; Carassius auratus

Presented at the IV Miguel R. Covian Symposium, Ribeirão Preto, SP, Brazil, May 23-25, 2008.

Research supported by CNPq (\#300499/2004-3) and FAPESP (\#2007/06041-0).

Received July 27, 2008. Accepted January 29, 2009

\section{Introduction}

The cerebellum is traditionally described as playing a key role in skeletal motor responses, motor learning and memory processes ranging from simple forms of sensorimotor learning to more complex, higher-order processes such as spatial cognition $(1,2)$. There is growing evidence that the cerebellum of mammals is also involved in emotional behaviors as part of an integrated network that regulates fear responses $(3,4)$. Moreover, it has been reported that the cerebellar vermis is connected to several limbic areas and is involved in emotional learning, for example active avoidance $(5,6)$.

Although little is known about the emotional behaviors of non-mammals, neuroanatomical studies have revealed that the neuronal organization, basic circuitry and neurophysiologic characteristics of the cerebellum of teleost fish are similar to those of the mammalian cerebellum $(6,7)$. Also, teleosts are suitable for studies with histamine because the central histaminergic system of fish has only one area of projection to the telencephalon $(8,9)$.

The involvement of histamine, a neurotransmitter, in various learning and memory processes in the brain has also been described; however, investigations in fish have 
reported contradictory results. Cofiel and Mattioli (10) have suggested that the $\mathrm{H}_{2}$ receptor antagonist zolantidine impairs inhibitory avoidance learning and memory in goldfish. Faganello and Mattioli (11) reported that chlorpheniramine facilitates inhibitory avoidance in goldfish submitted to telencephalic ablation.

Blandina et al. (12) have suggested that the facilitatory or inhibitory effects of histamine on learning and memory processes are related, among other factors, to the brain structure involved and to the nature of the task performed. Thus, the purpose of the present study was to determine the pharmacological effect of post-training administration of the histaminergic precursor L-histidine ( $\mathrm{LH}$ ) on the memory consolidation of inhibitory avoidance by Carassius auratus submitted to cerebellar ablation.

\section{Material and Methods}

\section{Subjects}

Goldfish (Carassius auratus) of unspecified sex, weighing between 8 and $14 \mathrm{~g}$, were used. The fish were purchased from a single source. Before the experiment, the animals were kept in 500-L tanks in the laboratory for 2 weeks for disease control.

The water was maintained at approximately $22^{\circ} \mathrm{C}$ and was continuously filtered and oxygenated under a natural light cycle. The animals were fed flake food (Fast Color, Formosa) daily in the morning until the surgery was performed. Individual fish were identified by physical characteristics such as color, size and tail shape.

\section{Surgical procedure}

The 58 animals were randomly divided into two groups: cerebellar ablation was performed in one group and sham surgery (leaving the cerebellum intact) in the second group (Figure 1).

The fish were anesthetized with an aqueous solution of $0.8 \mathrm{~g} / \mathrm{L}$ tricaine methanesulfonate (TMS) (3-aminobenzoic acid ethyl ester methanesulfonate, Sigma, USA). As soon as motor activity and gill movement ceased, the fish were

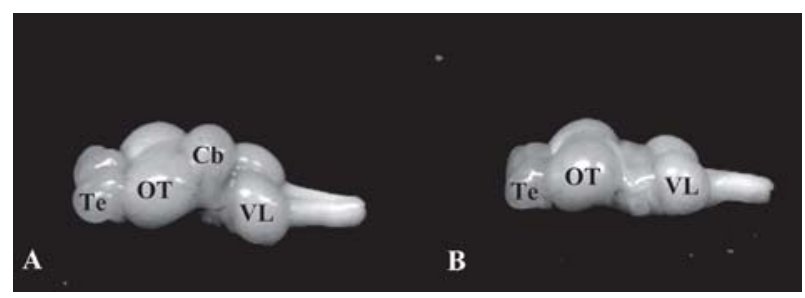

Figure 1. $A$, Normal brain, and $B$, cerebellum-ablated brain. Te $=$ telencephalon; $\mathrm{OT}=$ optic tectum; $\mathrm{Cb}=$ cerebellum; $\mathrm{VL}=$ vagal lobe. wrapped in wet gauze and placed on a stand. Water plus anesthesia was maintained by continuously perfusing the animals through the mouth.

The surgical procedure has been described (13). Briefly, after an incision in the skull the cerebellum was carefully aspirated through a pipette connected to a vacuum pump (Microbomba Nevoni Standard, NSR Ind., Com. and Repr. Ltda., Brazil). After cerebellar ablation, the skull was closed with fast drying dental acrylic resin (Acrílico Auto-Polimerizante Clássico, JET, Brazil, and Líquido Acrílico AutoPolimerizável, Dental VIPI Ltda., Brazil) and the wound was cleaned with methylene blue. Next, the TMS solution was replaced with water until spontaneous gill movement returned. The fish were then placed in maintenance aquaria for 3 days for recovery before the experimental sessions. Preventive fungicide/bactericidal and parasitic (Labcon Aqualife; Alcon, Brazil) treatment was used for disease control.

\section{Experimental aquarium}

A rectangular aquarium divided into two compartments was used. Each compartment was $15 \mathrm{~cm}$ high, $10 \mathrm{~cm}$ wide, and $45 \mathrm{~cm}$ long. One compartment was black and the other white. A guillotine door was used to separate the compartments. In the black compartment, a pulley was used to release a $45 \mathrm{~g}$ weight from a height of $15 \mathrm{~cm}$ above the water surface at a distance of $5 \mathrm{~cm}$ from the compartment's edge.

\section{Behavioral procedure}

The behavioral procedure was applied over three consecutive days. On the first day (habituation session), the fish were placed individually in the white compartment for $30 \mathrm{~s}$. The guillotine door was then opened and the animal was allowed to explore the aquarium for $10 \mathrm{~min}$, with free access to both compartments.

On the second day (training day), each fish was placed individually in the white compartment for $30 \mathrm{~s}$. The guillotine door was then opened and the animal had $5 \mathrm{~min}$ to move to the black compartment. After the animal entered the black compartment, the weight was released in front of it. If the animal did not return to the white compartment, it was gently coaxed back and the guillotine door was closed immediately after the fish returned to the white compartment. The procedure was repeated four more times (T1, $\mathrm{T} 2, \mathrm{~T} 3, \mathrm{~T} 4$, and T5) on the training day.

The time elapsed from the moment the door was lifted to the moment the animal entered the dark compartment was recorded in seconds (latency). The animal was considered to be inside the black compartment when its dorsal fin crossed the dividing line between compartments. If the 
animals failed to cross, the guillotine door was closed and another training attempt was started. Immediately after the training session, the fish were placed back in the original aquarium. After $10 \mathrm{~min}$, the pharmacological treatment was administered.

The test was conducted $24 \mathrm{~h}$ after the training session (third day) and latency was recorded in seconds. Training and testing latencies were recorded and compared as an indicator of behavioral learning and memory.

\section{Pharmacological treatment and injection procedure}

L-histidine (1 mol; Sigma) was dissolved in saline. The resulting solution was used at a dose of $100 \mathrm{mg} / \mathrm{kg}$ body weight, because a previous study indicated that this dose facilitated learning and memory in C. auratus (14). LH was chosen for its ability to quickly cross the blood-brain barrier (15). Saline was used as the experimental control. One milliliter of either the LH or control solution (blind-coded) was injected intraperitoneally (ip) per kg of body weight 10 min after the training session using a polyethylene tube attached to a $100-\mu \mathrm{L}$ Hamilton syringe $(710 \mathrm{~N})$ fitted with a dental needle. LH and saline were kept under refrigeration in coded tubes until they were used, so that the researcher was not aware of the treatment being administered at the time of the experiments.

The fish submitted to cerebellar ablation were divided into two groups, one treated with $\mathrm{LH}(\mathrm{A}-\mathrm{LH}, \mathrm{N}=15)$ and the other with saline ( $A-S A L, N=14)$. The fish submitted to sham surgery also received either $\mathrm{LH}(\mathrm{S}-\mathrm{LH}, \mathrm{N}=14)$ or saline (S-SAL, $N=15$ ).

\section{Histological analysis}

After the experimental procedures, the animals were anesthetized and decapitated. The brains were removed, fixed in $10 \%$ formalin for at least 5 days and then cut into $50-\mu \mathrm{m}$ sections with a cryostat. Histological analysis was carried out to verify that the cerebellum had been completely removed without injury to other areas.

\section{Statistical analysis}

Latency in the 5 training trials and on the test day was initially analyzed using the Levene test for homogeneity of variance. Data were transformed to $\log _{10}$ and analyzed by ANOVA followed by the Student-Newman-Keuls test $(P<$ 0.05).

\section{Results}

Figure 2 shows the mean latency ( \pm SEM) for the training trials and test procedure. Two-factor ANOVA (Factor A: treatment; Factor B: day) showed a statistically significant difference in latency between the days $\left(\mathrm{F}_{(5,341)}=\right.$ 13.87, $P<0.0001$ ) and the interaction of factors (training and treatment) $\left(F_{(15,341)}=3.60, P<0.0001\right)$. However, the difference in latency between treatments was not significant $\left(F_{(3,341)}=1.63, P=0.191\right)$. The Student-NewmanKeuls test revealed that latency was significantly increased in T5 when compared with T1 for all groups, showing that all were able to learn the task $(P<0.05)$.

For the test, the Student-Newman-Keuls test $(P<0.05)$ showed significantly lower latencies for the A-LH and S-

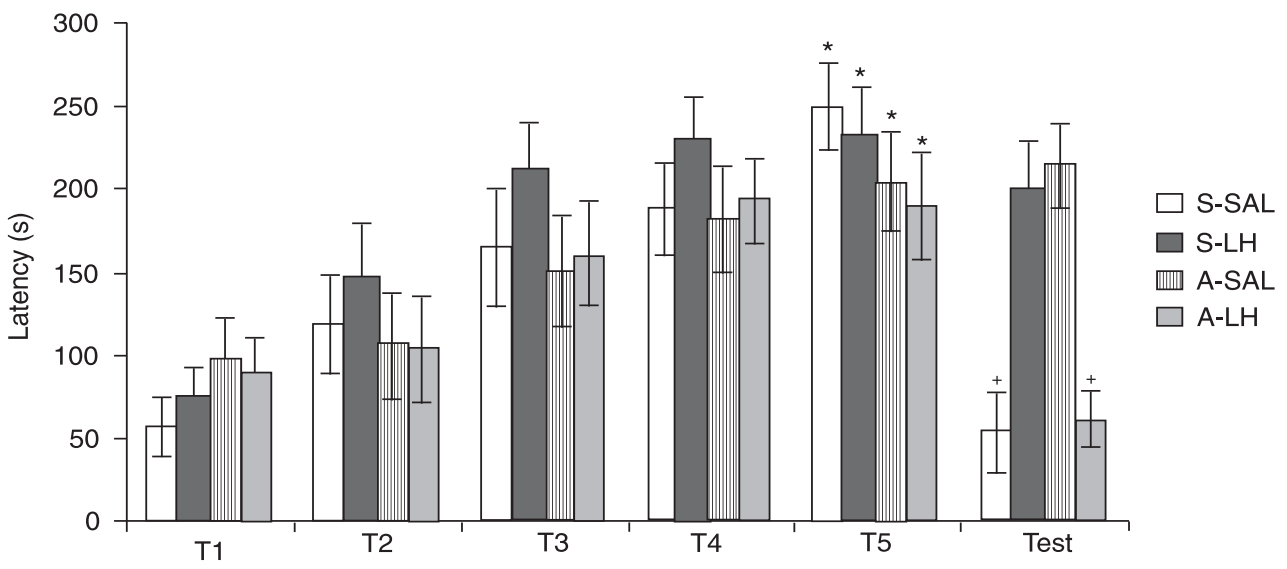

Figure 2. Mean ( \pm SEM) of latency to enter the black compartment in inhibitory avoidance procedure. T1, T2, T3, T4, and T5 correspond to the five trials on the training day. Sham groups were treated with saline (S-SAL, N = 15) or L-histidine $(\mathrm{S}-\mathrm{LH}, \mathrm{N}=14)$ and the groups with cerebellar ablation received saline (A-SAL, $N=14)$ or L-histidine $(A-L H, N=15)$. ${ }^{*}<<0.05$ compared to T1; ${ }^{+} P$ $<0.05$ compared to T5 (Student-Newman-Keuls test). 
SAL groups compared to the A-SAL and S-LH groups, showing that ablation of the cerebellum facilitated the retention of inhibitory avoidance and that $\mathrm{LH}$ reversed the effect of ablation (Figure 2).

\section{Discussion}

In this study, $C$. auratus fish were trained in an inhibitory avoidance task. In this procedure, learning is inferred when the animal reduces its preference for dark places, which is an innate behavior of the species (16), associating the black compartment with an aversive experience. Several studies have used this model to investigate the action of different drugs on learning and memory processes and on processes of functional recovery in goldfish, indicating that the model is appropriate for this purpose $(11,17,18)$.

The present results indicate that all groups were able to acquire inhibitory avoidance, suggesting that cerebellar ablation does not impair learning. A previous study has also shown that goldfish submitted to cerebellar ablation were able to acquire a conditioned bradycardia response (emotional conditioning) (19). In addition, goldfish submitted to telencephalic ablation have been shown to acquire inhibitory avoidance (17). In contrast, other studies have shown that complete removal of the cerebellum affected the learning of classical conditioning by goldfish $(20,21)$. Since inhibitory avoidance is a defensive behavior (22), we believe that the presence of inhibitory fear-mediating circuits in the mesencephalon, diencephalon and telencephaIon may explain why the fish submitted to cerebellar ablation were able to learn their task.

Several studies have shown that histamine affects neural plasticity and is therefore associated with functional recovery. Moreover, histamine has been suggested to be a neural substrate for reinforcement control, memory processes and emotional learning (11).

Hasenöhrl et al. (23) observed that intra-accumbens injection of histamine elicited a positive response in an inhibitory avoidance task; moreover, it induced conditioned place-preference, indicating a reinforcing action of histamine. Similarly, both systemic and intracerebroventricular administration of $\alpha$-fluormethylhistidine delayed the acquisition of active avoidance in mice (24). In other studies, Medalha et al. (18) reported that chlorpheniramine facilitates inhibitory avoidance training in goldfish in a doserelated manner.

The present results could be explained by the involvement of the central histaminergic system in the diencephalon in tasks having emotional components such as aversion, stress and fear. Ferretti et al. (25) found that stress induces the release of histamine in the hypothalamus of rats. In another study, the intraventricular administration of histamine caused an increase in the hypothalamic levels of tritiated histamine and a dose-dependent inhibition in avoidance conditioning in rats (26). Histamine levels were also shown to be significantly higher in the diencephalon of rats submitted to acute stress by confinement in a tight cage for $1 \mathrm{~h}$ (27).

Although it is difficult to compare the central nervous system of goldfish and mammals (20), anatomical and functional studies have shown the existence of similarities between certain structures of the mammalian brain and the three major telencephalic cell groups in teleosts (dorsal and ventral nucleus and lateral telencephalon). The lateral pallium is associated with spatial and temporal memory, and appears to be homologous to the hippocampus of vertebrates, while the medial pallium (MP) is related to emotional memory and has been suggested to be homologous to the amygdala of mammals $(28,29)$. Furthermore, recent studies have demonstrated the existence of connections between the cerebellum and the MP in goldfish and other teleost fish $(30,31)$.

In a study on goldfish submitted to telencephalic ablation, blockade of $\mathrm{H}_{1}$ by chlorpheniramine impaired consolidation of the conditioning memory of inhibitory avoidance (11). Alvarez and Ruarte (32) reported that local administration of histamine in the basolateral nucleus of the amygdala of mice reduced latency in an avoidance inhibitory model, indicating that histamine affects learning.

Similar results were obtained in the present study, in which the A-LH group failed to perform the avoidance task $24 \mathrm{~h}$ after training. Moreover, LH had an opposite effect on memory consolidation of inhibitory avoidance in the sham surgery group. This could be explained by an effect of LH on the MP after the connection between cerebellum and MP is disrupted, preventing the consolidation of inhibitory avoidance memory. These results support other evidence that $\mathrm{LH}$ exerts an effect on the consolidation of inhibitory avoidance memory in limbic structures. However, further studies are needed.

Brandão et al. (33) have proposed that the roof of the mesencephalon has local circuits capable of generating defensive behaviors associated with fear and anxiety, which are directly related to inhibitory avoidance. However, other higher brain structures are necessary to achieve the control of the complex behaviors related to fear. For example, connection of the inferior colliculus with the amygdala serves as an important filter for the aversive nature of sensory information (32). In addition, several studies have shown the existence of anatomical connections between the cerebellum and limbic areas, including the nucleus accumbens, hippocampus, locus ceruleus, ventral teg- 
mental area, periaqueductal gray matter, and amygdala (4). Sacchetti et al. (34) have proposed that the amygdala and cerebellum are functionally interconnected during aversive learning.

Amygdala lesions cause a great reduction of fear and aggressive behaviors, while stimulation of the amygdala induces fear responses in animals and a state of fear in animals and humans (4). Electrical stimulation of the cerebellar vermis of rats and cats after neurosurgery showed that the cerebellum modulates behavioral activities in the amygdala (35). Studies of rats submitted to cerebellectomy using an experimental model of inhibitory avoidance have indicated that the cerebellum is involved in the process of consolidation of emotional memories, but that it is not the place of memory recovery $(36,37)$.

The results obtained for the S-SAL group suggest that the fish were able to learn the task, but did not recall the information $24 \mathrm{~h}$ after training. Similar findings have been reported in several other studies $(10,11,17,18)$. Thus, we

\section{References}

1. Lalonde R, Botez MI. The cerebellum and learning processes in animals. Brain Res Brain Res Rev 1990; 15: 325332.

2. Rodriguez F, Duran E, Gomez A, Ocana FM, Alvarez E, Jimenez-Moya $F$, et al. Cognitive and emotional functions of the teleost fish cerebellum. Brain Res Bull 2005; 66: 365370.

3. Sacchetti B, Baldi E, Lorenzini CA, Bucherelli C. Cerebellar role in fear-conditioning consolidation. Proc Natl Acad Sci U S A 2002; 99: 8406-8411.

4. Sacchetti B, Scelfo B, Strata P. The cerebellum: synaptic changes and fear conditioning. Neuroscientist 2005; 11 : 217-227.

5. Kaplan $\mathrm{H}$, Aronson LR. Function of forebrain and cerebellum in learning in the teleost Tilapia heudelotii macrocephala. Bull Am Mus Nat Hist 1969; 142: 141-208.

6. Berntson GG, Torelli MW. The paleocerebellum and the integration of behavioral function. Physiol Psychol 1982; 10: 2-12.

7. Aronson LR, Herberman R. Persistence of a conditioned response in the cichlid fish, Tilapia macrocephala, after forebrain and cerebellar ablations. Anat Rec 1960; 138: 332.

8. Ekstrom P, Holmqvist BI, Panula P. Histamine-immunoreactive neurons in the brain of the teleost Gasterosteus acuteatus: Correlations with hypothalamic tyrosine hydroxylase and serotonin-immunoreactive neurons. J Chem Neuroanat 1995; 8: 74-85.

9. Peitsaro N, Kaslin J, Anichtchik OV, Panula P. Modulation of the histaminergic system and behaviour by alphafluoromethylhistidine in zebrafish. J Neurochem 2003; 86: $432-441$

10. Cofiel LP, Mattioli R. Involvement of histamine receptors in believe that the results for the fish in the A-SAL and S-SAL groups were opposite in terms of memory consolidation of the inhibitory avoidance task due to the absence of cerebellar modulation in limbic structures in the ablation group, especially in the MP, which is thought to be homologous to the amygdala (29-31).

The results of the present study suggest that L-histidine impairs memory consolidation and/or reduces the interpretation of the aversive stimulus in inhibitory avoidance conditioning, and that this process is mediated by the medial pallium. In conclusion, the present findings indicated an involvement of the histaminergic system in memory process in goldfish.

\section{Acknowledgments}

We thank Teresa de Fátima Fatori Piassi for providing technical assistance. the acquisition of inhibitory avoidance in Carassius auratus. Prog Neuropsychopharmacol Biol Psychiatry 2006; 30: 1246-1250.

11. Faganello FR, Mattioli R. Chlorpheniramine facilitates inhibitory avoidance in teleosts submitted to telencephalic ablation. Braz J Med Biol Res 2008; 41: 398-402.

12. Blandina P, Efoudebe M, Cenni G, Mannaioni P, Passani MB. Acetylcholine, histamine, and cognition: two sides of the same coin. Learn Mem 2004; 11: 1-8.

13. Yoshida M, Okamura I, Uematsu K. Involvement of the cerebellum in classical fear conditioning in goldfish. Behav Brain Res 2004; 153: 143-148.

14. Medalha CC, Mattioli R. Involvement of the histaminergic system on appetitive learning and its interaction with haloperidol in goldfish. Neurosci Lett 2007; 418: 195-200.

15. Leurs R, Smit MJ, Timmerman H. Molecular pharmacological aspects of histamine receptors. Pharmacol Ther 1995; 66: 413-463.

16. Serra EL, Medalha CC, Mattioli R. Natural preference of zebrafish (Danio rerio) for a dark environment. Braz J Med Biol Res 1999; 32: 1551-1553.

17. Faganello FR, Medalha CC, Mattioli R. Haloperidol and chlorpheniramine interaction in inhibitory avoidance in goldfish. Behav Brain Res 2003; 147: 83-88.

18. Medalha CC, Coelho JL, Mattioli R. Analysis of the role of histamine in inhibitory avoidance in goldfish. Prog Neuropsychopharmacol Biol Psychiatry 2000; 24: 295-305.

19. Salas C, Broglio C, Duran E, Gomez A, Ocana FM, JimenezMoya $F$, et al. Neuropsychology of learning and memory in teleost fish. Zebrafish 2006; 3: 157-171.

20. Álvarez E, Gómez A, Durán E, Ocaña FM, Jiménez-Moya F, Broglio C, et al. Brain substrates of "eyeblink" classical conditioning in goldfish. Acta Neurobiol Exp 2003; 63: 62. 
21. Álvarez E, Gómez A, Rodríguez F, González JA, GonzálezPardo $\mathrm{H}$, Arias $\mathrm{JL}$, et al. Effects of classical conditioning on cytochrome oxidase activity in the cerebellum of goldfish. International Behavioral Neuroscience Meeting. 2002 Jun 19-23; Capri. p 49 (Abstract 68).

22. Misslin R. The defense system of fear: behavior and neurocircuitry. Neurophysiol Clin 2003; 33: 55-66.

23. Hasenöhrl RU, Kuhlen A, Frisch C, Galosi R, Brandao ML, Huston JP. Comparison of intra-accumbens injection of histamine with histamine $\mathrm{H} 1$-receptor antagonist chlorpheniramine in effects on reinforcement and memory parameters. Behav Brain Res 2001; 124: 203-211.

24. Kamei C, Okumura $Y$, Tasaka K. Influence of histamine depletion on learning and memory recollection in rats. Psychopharmacology 1993; 111: 376-382.

25. Ferretti $C$, Blengio M, Ghi P, Adage T, Portaleone P, Ricci GS. Hypothalamic histamine release in normal and stressed rats is affected by sex and aging. Pharmacol Biochem Behav 1998; 59: 255-260.

26. Tasaka K, Kamei C, Akahori H, Kitazumi K. The effects of histamine and some related compounds on conditioned avoidance response in rats. Life Sci 1985; 37: 2005-2014.

27. Ito C, Shen H, Toyota H, Kubota Y, Sakurai E, Watanabe T, et al. Effects of the acute and chronic restraint stresses on the central histaminergic neuron system of Fischer rat. Neurosci Lett 1999; 262: 143-145.

28. Butler AB. Topography and topology of the teleost telencephalon: a paradox resolved. Neurosci Lett 2000; 293: 9598.

29. Portavella M, Vargas JP, Torres B, Salas C. The effects of telencephalic pallial lesions on spatial, temporal, and emo- tional learning in goldfish. Brain Res Bull 2002; 57: 397-399.

30. Northcutt RG. Connections of the lateral and medial divisions of the goldfish telencephalic pallium. J Comp Neurol 2006; 494: 903-943.

31. Yang CY, Yoshimoto M, Xue HG, Yamamoto N, Imura K, Sawai $\mathrm{N}$, et al. Fiber connections of the lateral valvular nucleus in a percomorph teleost, tilapia (Oreochromis niloticus). J Comp Neurol 2004; 474: 209-226.

32. Alvarez EO, Ruarte MB. Glutamic acid and histamine-sensitive neurons in the ventral hippocampus and the basolateral amygdala of the rat: functional interaction on memory and learning processes. Behav Brain Res 2004; 152: 209-219.

33. Brandão ML, Troncoso AC, de Souza Silva MA, Huston JP. The relevance of neuronal substrates of defense in the midbrain tectum to anxiety and stress: empirical and conceptual considerations. Eur J Pharmacol 2003; 463: 225233.

34. Sacchetti B, Sacco T, Strata P. Reversible inactivation of amygdala and cerebellum but not perirhinal cortex impairs reactivated fear memories. Eur J Neurosci 2007; 25: 28752884.

35. Heath RG, Dempesy CW, Fontana CJ, Myers WA. Cerebellar stimulation: effects on septal region, hippocampus, and amygdala of cats and rats. Biol Psychiatry 1978; 13: 501529.

36. Dahhaoui M, Caston J, Auvray N, Reber A. Role of the cerebellum in an avoidance conditioning task in the rat. Physiol Behav 1990; 47: 1175-1180.

37. Guillaumin S, Dahhaoui M, Caston J. Cerebellum and memory: an experimental study in the rat using a passive avoidance conditioning test. Physiol Behav 1991; 49: 507-511. 